\title{
Pulse cyclophosphamide therapy for inflammatory bowel disease
}

\author{
Zsolt Barta, László Tóth, Margit Zeher
}

Zsolt Barta, Margit Zeher, $3^{\text {rd }}$ Department of Medicine, Faculty of Medicine, Medical and Health Science Centre, University of Debrecen, Debrecen, Hungary

László Tóth, Department of Pathology, Faculty of Medicine, Medical and Health Science Centre, University of Debrecen, Debrecen, Hungary

Correspondence to: Zsolt Barta, MD, $3^{\text {rd }}$ Department of Medicine, Faculty of Medicine, Medical and Health Science Centre, University of Debrecen, H-4012 Debrecen, Móricz Zs. krt 22, Hungary.mailto:barta@iiibel.dote.hu

Telephone: +36-52-414969 Fax: +36-52-414969

Received: 2005-04-05 Accepted: 2005-07-20

\section{Abstract}

AIM: To assess the efficacy of intravenous cyclophosphamide pulse therapy for refractory inflammatory bowel disease (IBD).

METHODS: We included in our cohort eight patients with (moderate/severe) steroid refractory IBD (4 with ulcerative colitis and 4 with Crohn's disease). They all received 6 cycles of intravenous cyclophosphamide (800 $\mathrm{mg}$ ) per month.

RESULTS: Patients entered into remission after the second/third cyclophosphamide pulse. Disease activity decreased. There were no side effects and toxicity. All the patients went into long lasting remission. All Crohn's disease patients and 3 of 4 ulcerative colitis patients achieved complete remission. One patient with ulcerative colitis showed an impressive clinical response but did not enter into remission. For the maintenance, patients with Crohn's disease were treated with methotrexate $(15 \mathrm{mg} / \mathrm{wk})$ and patients with ulcerative colitis were treated with azathioprine $(2.5 \mathrm{mg} / \mathrm{kg}$ body weight $/ \mathrm{d})$.

CONCLUSION: Remission was maintained in all patients for 6 mo on the average. The drug was well tolerated. These findings suggest that aggressive immunosuppressive therapy may be useful in some refractory patients and further controlled study should be considered in order to fully evaluate this type of treatment as a potential therapy for IBD.

(c) 2006 The WJG Press. All rights reserved.

Key words: Crohn's disease; Ulcerative colitis; Cyclophosphamide

Barta Z, Tóth L, Zeher M. Pulse cyclophosphamide therapy for inflammatory bowel disease. World J Gastroenterol 2006; 12(8): 1278-1280

http://www.wjgnet.com/1007-9327/12/1278.asp

\section{INTRODUCTION}

Crohn's disease (CD) and ulcerative colitis (UC), collectively referred to as inflammatory bowel disease (IBD), are relatively common inflammatory diseases of the gastrointestinal (GI) tract. Histopathologically and anatomically, these two conditions are distinct, with $\mathrm{CD}$ characterized by transmural inflammation that can occur throughout the GI tract, and UC characterized by more superficial inflammation confined to the colon and rectum. The etiology and pathogenesis of IBD are not yet completely understood. Although the details of the pathogenesis of IBD remain elusive, it is believed that exposure of genetically susceptible individuals to environmental factors (e.g., dietary antigens, luminal bacteria) seems to be an important factor for the development and chronicity.

Pharmacotherapy for IBD has essentially been unchanged for over twenty years, with therapy based on 5-aminosalicylic acid (5-ASA) preparations, corticosteroids, antibiotics and immunosuppressants. Many of the controversies about optimal use of these drugs in IBD arise as a consequence of methodological deficiencies in many of the trials combined with the difficulty in consistent patient selection due to the heterogeneous nature of both UC and CD. Current therapy for IBD is neither sufficient nor disease-modifying. The firstline therapy for IBD flares is typically medical in nature. Long-term treatment with non-specific anti-inflammatory drugs such as aminosalicylates, corticosteroids and immunosuppressants is often accompanied with undesirable and potentially serious side effects. Glucocorticoids are a mainstay for the treatment of severe inflammatory bowel disease. Aminosalicylates are efficacious in the treatment of active mild to moderate disease. Infliximab, a chimeric monoclonal anti-TNF alpha antibody can be used in treatment of refractory Crohn's disease ${ }^{[i]}$. Novel biologically-driven therapies are targeted to specific pathophysiological processes, offering the potential for better treatment outcomes.

The management of refractory, severe IBD is yet an unsolved problem. Accurate assessment of specific organ involvement and disease severity is vital if we are 
going to tailor appropriate therapy for certain patient. In common with other disease, the aims of therapy for IBD fall into three categories, namely induction of remission, maintenance of remission, and prevention of relapse. All should be undertaken with minimal mortality and morbidity either from the disease itself or from the therapy

Cytotoxic drugs prevent cell division or cause cell death. They act predominantly on rapidly dividing cells such as $T$ lymphocytes, and are therefore immunosuppressive and anti-inflammatory. When cytotoxic drugs are initially used in the treatment of cancer, they have profound effects on the immune system. This "unwanted" side effect has subsequently been exploited for the treatment of nonmalignant disease where autoimmune mechanisms are considered important in the pathogenesis. Based on the previous observations of improvement in autoimmune diseases (i.e., vasculitides), cyclophosphamide can be the primary cytotoxic drug ${ }^{[2-4]}$. Pulse intravenous cyclophosphamide is probably equally effective as oral cyclophosphamide at inducing remission and this remission is usually maintained by continuing cyclophosphamide for 3-6 mo before changing to a combination of other per os therapy. Cyclophosphamide can be administered intravenously at $500-1000 \mathrm{mg} / \mathrm{m}^{2}$ pulses monthly. The optimal duration of treatment with intravenous cyclophosphamide has not been determined for IBD, but treatment for six months with monthly pulses would be typical, followed by maintenance therapy with azathioprine or methotrexate. Therapy must be continued to prevent relapse and for maintenance.

Only sporadic but promising cases are reported and experiences with cyclophosphamide in severe IBD are very limited but most patients entering into remission have no major adverse events or side effects ${ }^{[5]}$. We here report some other cases to enrich the experiences. We designed a noncontrolled prospective pilot study to investigate the effects of pulse cyclophosphamide therapy for IBD patients. The aim of this study was to examine the effect of this kind of therapy on UC and CD.

\section{MATERIALS AND METHODS}

\section{Patient selection and treatment}

All patients were recruited in this prospective uncontrolled pilot study from our out-patient clinic specializing in chronic inflammatory bowel diseases (at the $3^{\text {rd }}$ Department of Medicine, University of Debrecen). Between September 2002 and December 2003 we included in our cohort eight patients with (moderate/severe) steroid refractory IBD (four patients with CD and four with UC).

All patients were diagnosed according to the standard criteria and underwent endoscopy and/or radiological studies, including ileo-colonoscopy, CT and/or doublecontrast barium air enteroclysis during 6 mo of the study. Video endoscopy of the large intestine, including the terminal ileum, was performed before the first cyclophosphamide pulse and at wk 12. All the patients did not respond to conventional therapy (this was the only selection criteria for this study) and were treated with pulse cyclophosphamide therapy monthly (6 cycles). The bolus dose was applied independent of body weight. Cyclophosphamide $(800 \mathrm{mg})$ was given during a $4 \mathrm{~h}$ hospital stay in $500 \mathrm{~mL}$ physiologic or normal saline $(0.9 \%)$ in a period of 120 min. White blood cell (WBC) counts and urine tests for incidental microscopic haematuria were obtained on preand post-cyclophosphamide therapy day $(0,7,14)$.

\section{Dutcome measurement}

All the patients were informed of the potential risks and benefits of cyclophosphamide therapy and a written informed consent was given in advance. We defined treatment failure as any of the followings: lack of an initial response, relapse after an initial response, and intolerance to cyclophosphamide necessitating discontinuation of the drug. We used the modified Truelove and Witts activity index for ulcerative colitis and best index (Crohn's disease activity index) for Crohn's disease as others ${ }^{[6,7]}$. We used working definitions for the assessment of the response both in UC and CD. Active disease was defined as symptomatic UC with a Truelove-Witts score greater than 6 points and symptomatic CD with a CDAI score greater than 150 points. Significant (moderate-severe) relapse was defined as symptomatic UC with a Truelove-Witts score greater than 10 points and symptomatic CD with a CDAI score greater than 150 points and/or the need for systemic steroid therapy (including oral budesonide), and treatment failure was defined as relapse, colectomy or any serious adverse event.

\section{RESULTS}

Patient histories are summarized in Table 1. CD patients were all females aged 36-65 years (mean 49 years) and UC patients were all males aged 29-59 years (mean 40.25 years). Each patient received six monthly treatment. All patients were continued on a daily regimen of methyl prednisolone and the daily dose was decreased according to individual clinical activity. Azathioprine $(2.5 \mathrm{mg} / \mathrm{kg}$ body weight per day) and methotrexate (15 mg/wk) were initiated orally for $\mathrm{UC}$ and $\mathrm{CD}$ patients respectively to maintain remission following cyclophosphamide treatment.

The patients entered into remission after the second/ third cyclophosphamide pulse. Disease activity decreased. There were no side effects and no toxicity. All the patients went into long lasting remission. Remission seemed stable (except for case 5: relapse after $6 \mathrm{mo}$ ). These findings suggested that aggressive immunosuppressive therapy might be useful in some refractory patients and further controlled study should be considered in order to fully evaluate this type of treatment as a potential therapy for IBD.

\section{DISCUSSION}

Current therapy for IBD is unsolved. Many drugs are prescribed for inflammatory bowel disease, either for treating active disease or for maintaining remission. However, no drug provides a completely satisfactory response in a large percentage of patients. Corticosteroids (steroids) at dosages equivalent to $40-60 \mathrm{mg} / \mathrm{d}$ prednisone are commonly prescribed for acute exacerbations of Crohn's disease and ulcerative colitis. Steroids are not 


\section{Table 1 Patient histories}

\begin{tabular}{|c|c|c|c|c|c|c|c|}
\hline $\begin{array}{l}\text { Patient } \\
\text { No }\end{array}$ & Age/sex & Disease & $\begin{array}{l}\text { Duration } \\
\text { of IBD (yr) }\end{array}$ & Localization & $\begin{array}{l}\text { CDAI before/after } \\
6 \text { cycles }\end{array}$ & $\begin{array}{l}\text { UC-DAI } \\
\text { before/after } 6 \text { cycles }\end{array}$ & $\begin{array}{l}\text { Maintenance } \\
\text { therapy for remission }\end{array}$ \\
\hline 1 & $46 /$ female & $\mathrm{CD}$ & 26 & colon-rectum & $168 / 79$ & & methotrexate \\
\hline 2 & $65 /$ female & $\mathrm{CD}$ & 18 & ileum-colon-rectum & $231 / 86$ & & methotrexate \\
\hline 3 & $49 /$ female & $\mathrm{CD}$ & 22 & ileum-colon & $198 / 91$ & & methotrexate \\
\hline 4 & $36 /$ female & $\mathrm{CD}$ & 5 & ileum-colon & $242 / 98$ & & methotrexate \\
\hline 5 & $59 /$ male & UC & 5 & rectum & & $14 / 6$ & azathioprine \\
\hline 6 & $44 /$ male & UC & 5 & rectum & & $15 / 8$ & azathioprine \\
\hline 7 & $29 /$ male & UC & 4 & recto-sigmoid & & $13 / 6$ & azathioprine \\
\hline 8 & $29 /$ male & UC & 8 & recto-sigmoid & & $14 / 7$ & azathioprine \\
\hline
\end{tabular}

UC-DAI: Modified Truelove and Witts activity index for UC; CDAI: CD activity index; Methotrexate: 15 mg/wk; Azathioprine: 2.5 mg/kg body weight per day.

effective for maintenance of remission in either disease. However, some patients require long-term steroids for suppression of disease, particularly Crohn's disease. Taking steroids for a prolonged period can cause reversible or irreversible adverse effects ${ }^{[8-10]}$. These adverse effects are of sufficient concern to prompt consideration of alternative treatment strategies. Infliximab, human growth hormone, and other novel biotechnology treatments have been investigated as therapy for patients with inflammatory bowel disease. Although these biotechnology-derived treatments are promising, their cost is prohibitive for many patients. Because cyclophosphamide is effective for other inflammatory conditions and is relatively less expensive than some other agents, it is considered in the treatment of inflammatory bowel disease.

IBD continues to pose a challenge to clinicians. Over the past few years there have been significant advances in our understanding of its pathogenesis and treatment. These advances may lead to more specific and targeted treatments, with consequent improvements in clinical outcomes. Intravenous pulse cyclophosphamide therapy may be a safe and effective treatment for patients with severe IBD unresponsive to conventional treatment as a first-line adjunct to or replacement of systemic corticosteroids in the treatment of IBD. Last but not the least, costs of this kind of treatment are relatively low.

In conclusion, pulse cyclophosphamide therapy can be used in treatment of selected IBD patients. However, larger placebo-controlled studies in more diverse patient population are warranted.

\section{REFERENCES}

1 Arnott ID, McDonald D, Williams A, Ghosh S. Clinical use of Infliximab in Crohn's disease: the Edinburgh experience. Aliment Pharmacol Ther 2001; 15: 1639-1646

2 Riley P, Maillard SM, Wedderburn LR, Woo P, Murray KJ, Pilkington CA. Intravenous cyclophosphamide pulse therapy in juvenile dermatomyositis. A review of efficacy and safety. Rheumatology (Oxford) 2004; 43: 491-496

3 McCune WJ, Golbus J, Zeldes W, Bohlke P, Dunne R, Fox DA. Clinical and immunologic effects of monthly administration of intravenous cyclophosphamide in severe systemic lupus erythematosus. N Engl J Med 1988; 318: 1423-1431

4 Watts RA, Scott DG, Pusey CD, Lockwood CM. Vasculitis-aims of therapy. An overview. Rheumatology (Oxford) 2000; 39: 229-232

5 Stallmach A, Wittig BM, Moser C, Fischinger J, Duchmann R, Zeitz M. Safety and efficacy of intravenous pulse cyclophosphamide in acute steroid refractory inflammatory bowel disease. Gut 2003; 52: 377-382

6 Sands BE, Tremaine WJ, Sandborn WJ, Rutgeerts PJ, Hanauer SB, Mayer L, Targan SR, Podolsky DK. Infliximab in the treatment of severe, steroid-refractory ulcerative colitis: a pilot study. Inflamm Bowel Dis 2001; 7: 83-88

7 Drossman DA, Li Z, Leserman J, Patrick DL. Ulcerative colitis and Crohn's disease health status scales for research and clinical practice. J Clin Gastroenterol 1992; 15: 104-112

8 Daperno M, Sostegni R, Scaglione N, Ercole E, Rigazio C, Rocca R, Pera A. Outcome of a conservative approach in severe ulcerative colitis. Dig Liver Dis 2004; 36: 21-28

9 Kane SV, Schoenfeld P, Sandborn WJ, Tremaine W, Hofer $\mathrm{T}$, Feagan BG. The effectiveness of budesonide therapy for Crohn's disease. Aliment Pharmacol Ther 2002; 16: 1509-1517

10 Shimada T, Hiwatashi N, Yamazaki H, Kinouchi Y, Toyota T. Relationship between glucocorticoid receptor and response to glucocorticoid therapy in ulcerative colitis. Dis Colon Rectum 1997; 40: S54-S58

S- Editor Guo SY L- Editor Wang XL E- Editor Bi L 